\title{
New information on regional subsidence and soil fracturing in Mexico City Valley
}

\author{
G. Auvinet, E. Méndez-Sánchez, and M. Juárez-Camarena \\ Instituto de Ingeniería, UNAM, Mexico \\ Correspondence to: G. Auvinet (gauvinetg@iingen.unam.mx)
}

Published: 12 November 2015

\begin{abstract}
In this paper, updated information about regional subsidence in Mexico City downtown area is presented. Data obtained by R. Gayol in 1891, are compared with information obtained recently from surveys using the reference points of Sistema de Aguas de la Ciudad de México (2008) and on the elevation of a cloud of points on the ground surface determined using Light Detection and Ranging (LiDAR) technology. In addition, this paper provides an overview of recent data obtained from systematic studies focused on understanding soil fracturing associated with regional land subsidence and mapping of areas susceptible to cracking in Mexico City Valley.
\end{abstract}

\section{Introduction}

Mexico Valley lacustrine subsoil has an exceptionally high compressibility and low resistance. Additionally, a regional subsidence phenomenon is affecting the urban area since the early Twentieth Century. One consequence of this phenomenon is the generation of cracks in the soil in many places. Both problems, regional subsidence and soil fracturing represent a risk for the stability of buildings and affect the urban infrastructure.

The demographic development of Mexico City has created an accelerated demand for services, especially supply of drinking water. One of the cheapest ways to respond to this demand has been the exploitation of the aquifer underneath the urban area by pumping water from deep wells. This activity has produced a regional subsidence phenomenon and the cracking of the soil in the lacustrine and alluvial-lacustrine areas of Mexico City. Due to the high cost of other watersupply alternatives, it is expected that extraction of water from the local aquifer will continue for many years.

The regional subsidence in Mexico City has severe consequences. It affects the drainage system, transport infrastructure, foundations of buildings and generates serious risks to the population, since it induces other problems such as flooding of low areas. Therefore, although the regional subsidence is an ancient phenomenon, its study and analysis remain a priority nowadays, inasmuch as it has not been possible to control its basic cause, which frequently leads to adopt emergency solutions.

More and more frequently, cracks appear in the soil of Mexico City causing alarm among the population and damaging buildings. Therefore, since 2005, the Geocomputing Laboratory group of the Geotechnical Section of Instituto de Ingeniería, UNAM in collaboration with the Mexican Society for Geotechnical Engineering and with the support of municipal authorities has undertaken a systematic study of the phenomenon of soil cracking. The occurrence of cracking may result from any condition that causes important tension stresses in the soil (Auvinet, 2008) and the occurrence of cracking has different causes, including contraction of the lacustrine clays by drying, existence of tension stresses associated with buildings weight, hydraulic fracturing in areas of flooding, etc. However, the most important and destructive cracks are a direct consequence of regional subsidence that occurs in Mexico City as a result of pumping water from the aquifer. 


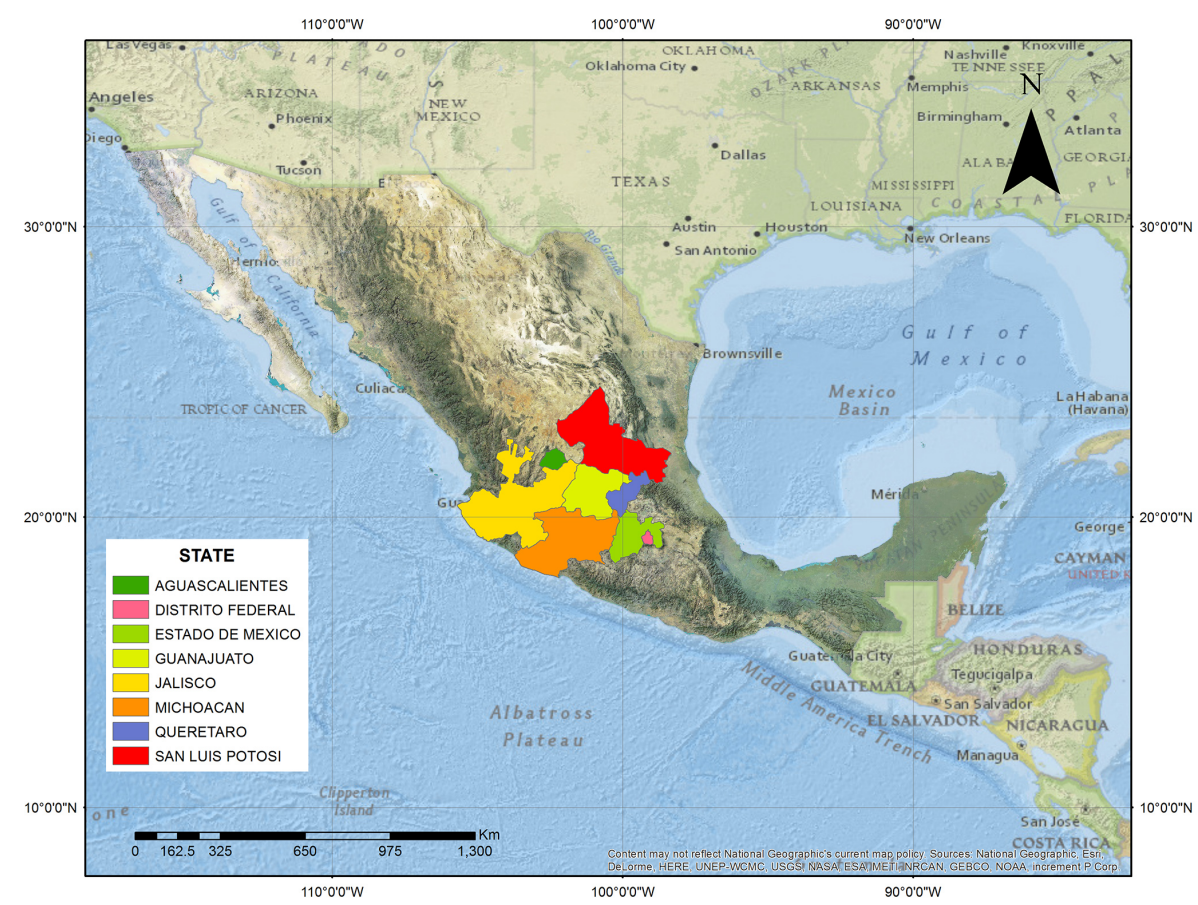

Figure 1. Spatial distribution of the phenomenon of soil cracking in Mexico.

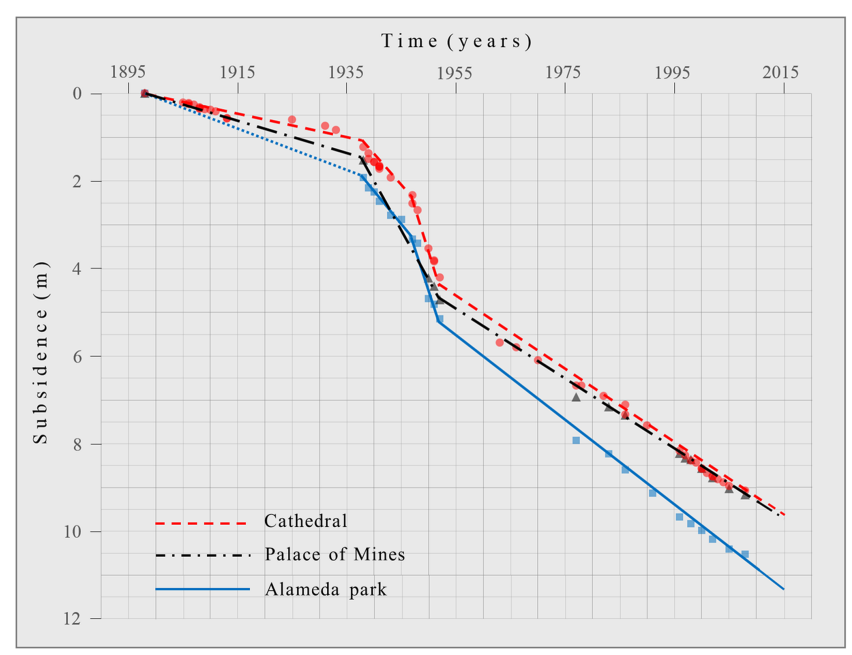

Figure 2. Evolution of subsidence for period 1898-2015.

\section{Previous studies}

The regional subsidence of Mexico basin was studied in the late nineteenth century by Téllez Pizarro (1899). In 1925, Roberto Gayol informed the Society of Engineers and Architects of Mexico that Mexico City was subsiding and that the probable cause was the "disturbance that the drainage of subsoil water was producing, in the bottom of Mexico basin". Gayol based his assertion on some surveys in Mexico City downtown and in the Texcoco Lake (1891).
Between 1920 and 1930, José A. Cuevas gave his support to the ideas of Gayol and asked Nabor Carrillo to study the influence of the pumping from water wells on subsidence. Carrillo (1948) explained the subsidence using newly developed techniques of Soil Mechanics and established that the cause of this phenomenon was the consolidation of clays due to the increase in effective stress caused by the drawdown of interstitial water pressure.

In 1952, the systematic study of subsoil and the first piezometric measurements made by Sandoval, Hiriart and Marsal, corroborated the findings of Nabor Carrillo. Also very meaningful were the investigations by Zeevaert and the periodical surveys and piezometric measurements performed since 1953 by Hydrological Commission of Mexico Basin Valley (CHCVM, SRH) and subsequently by the Water System of Mexico City (SACMEX).

Soil cracking is not exclusive of Mexico City, this phenomenon has spread to other states of the country (Estado de Mexico, Querétaro, Morelia, Silao, Aguascalientes, between others). In Fig. 1, the states of the country where the cracking phenomenon has been detected are indicated.

In Mexico City, due to increasing subsidence, soil fissuring that previously only occurred in the dry zone of formerLake of Texcoco has extended to the transition geotechnical zone of the city (0 to $20 \mathrm{~m}$ of lacustrine clay). This can be attributed to differential settlements between zones of soft and hard soils, damaging buildings and urban services. The problem of soil cracking in Mexico City Valley is of large magnitude and will require continued attention in the future. 


\section{Subsidence evaluation}

From the available historical documents, it has been possible to reconstruct the history of subsidence of the old downtown area of Mexico City. Analyzing graphs in Fig. 2 and in particular, those corresponding to the Cathedral and Alameda Central, it can be concluded that the history of subsidence has gone through four stages during the twentieth century and in the first decade of the current century while, in the Palace of Mines, the subsidence history has gone through only three stages. These stages correspond to different rates of water extraction.

Figure 3a shows the shaded relief model (SRM) built from topographical data obtained in 1891 by Gayol. The model corresponds to the area of the old "traza" (center) of Mexico City. The so-called "corographic" map of Federal District by Manuel Fernandez Leal (1899) was superimposed on the model. Figure $3 \mathrm{~b}$ shows the shaded relief model (SRM) constructed from a dense cloud of points obtained by scanning using the Light Detection and Ranging (LiDAR) technique by the National Institute of Geography Statistics and Computing (INEGI, 2010), corresponding to the old central area of Mexico City. Figure 4 shows the remnants of the buildings of the ceremonial precinct of the Mexica Empire and the trace of the Historic center of Mexico City superimposed on a shaded relief model, obtained by INEGI (2010).

Figure 5 shows an assessment of the magnitude of regional subsidence, both in the west-east direction along Tacuba Avenue and in the North-South direction along José María Pino Suárez Avenue, in the historical center of Mexico City for the 1891-2010 period (119 years).

\section{Soil cracking associated to regional subsidence}

Cracks originating in areas of abrupt transition between compressible and hard soils, are a direct consequence of the regional subsidence of Mexico Valley as a result of pumping water from the local aquifer.

These cracks are very destructive; they present a step towards the area of greatest settlement and are generally parallel to the elevation contours at the foot of the mountains, hills or outcrops of rock or rigid materials (Fig. 6).

The cracking phenomenon associated with regional subsidence in areas of abrupt transition takes a particular importance in the area surrounding Santa Catarina range, Peñón Viejo-Peñón Márquez hill, Guerrero hill, Peñón de los Baños hill, Chimalhuacán hill, Xico hill and in the northern limit of the Chichinautzin range. Figure 7 shows the principal zones where soil is most suceptible to cracking as defined from the gradient of variation of clay layers thickness and recorded differential settlements.

Photographs of Fig. 8 show the destructive capacity of soil cracking associated with regional subsidence.

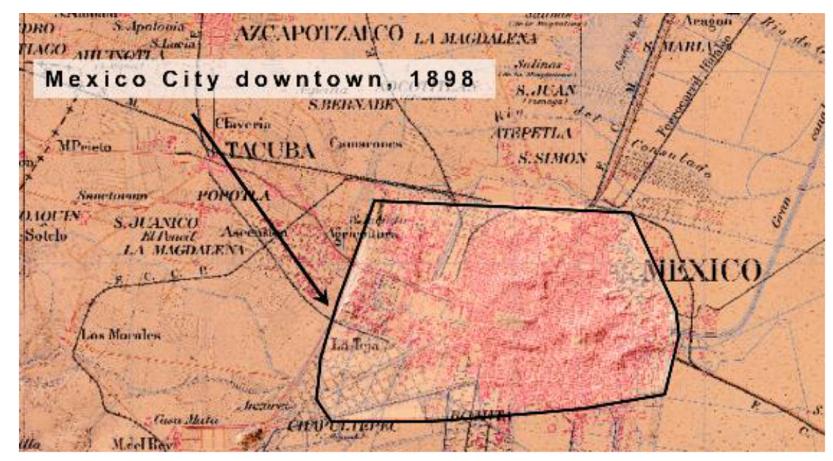

a) Old map (1898)

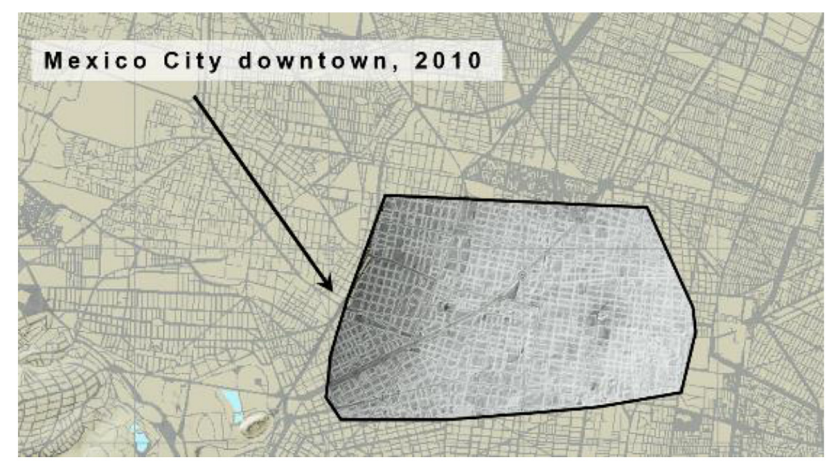

b) Recent map (2010)

Figure 3. Maps of Mexico City downtown area over a shading relief model.

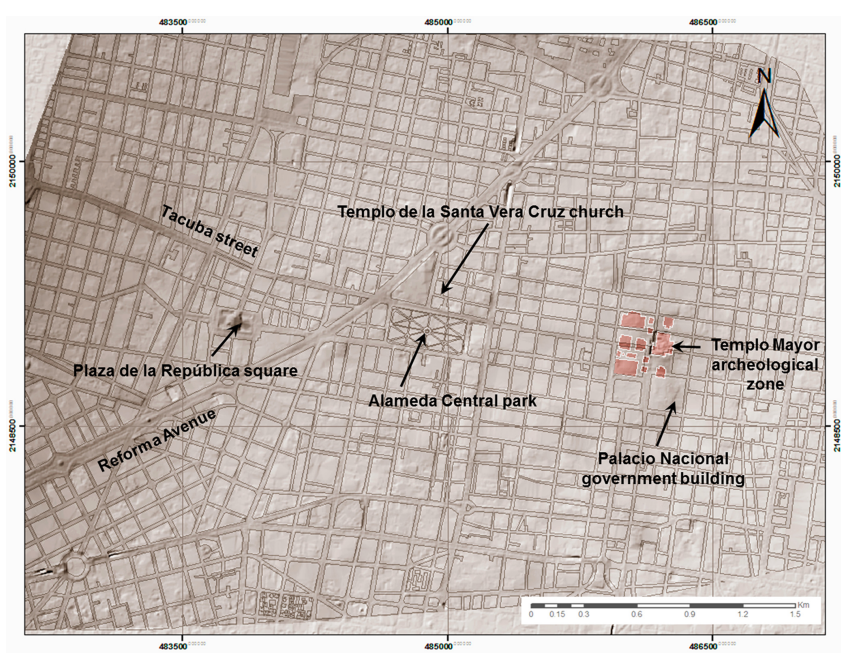

Figure 4. Mexica constructions remnants in Mexico City downtown area over a raster model obtained from LiDAR data.

\section{Conclusions}

The effort undertaken by different groups and in particular by the Geocomputing Laboratory of the Engineering Institute, UNAM to achieve a satisfactory evaluation of the phenomenon of subsidence, as well as other aspects of geotechnical problems such as soil fissuring has given useful and 


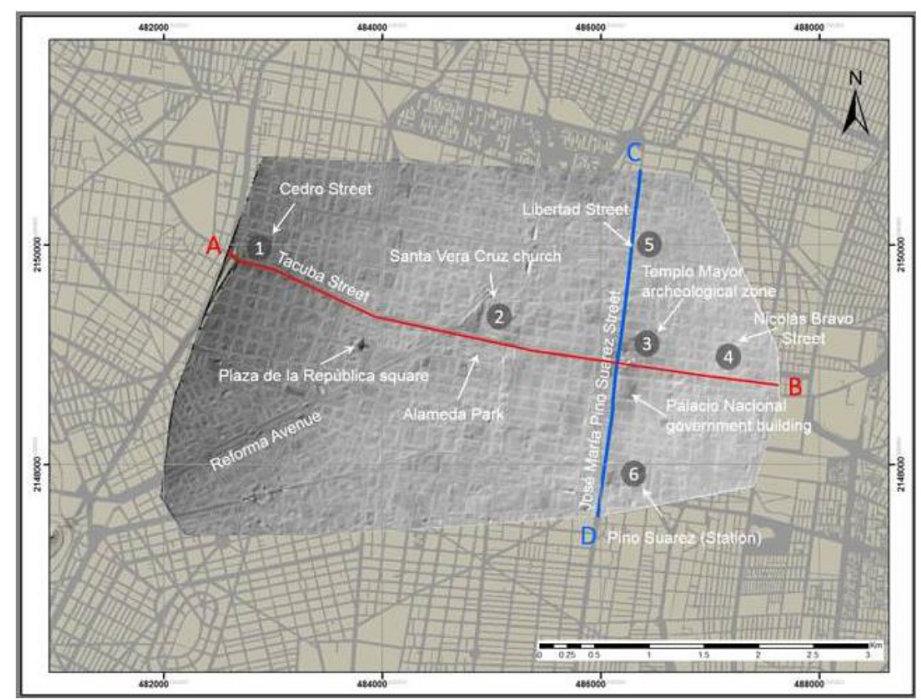

\section{a) Location of profiles}

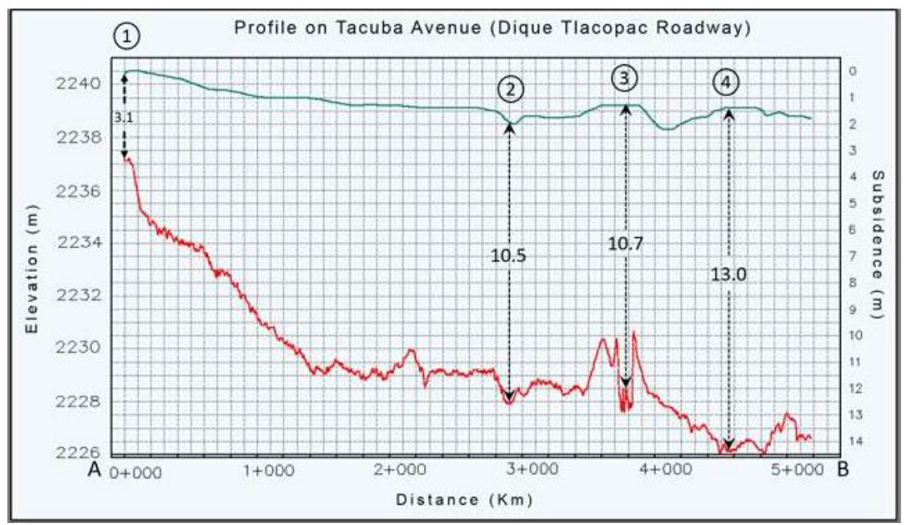

b) Profile along Tacuba Avenue (A-B)

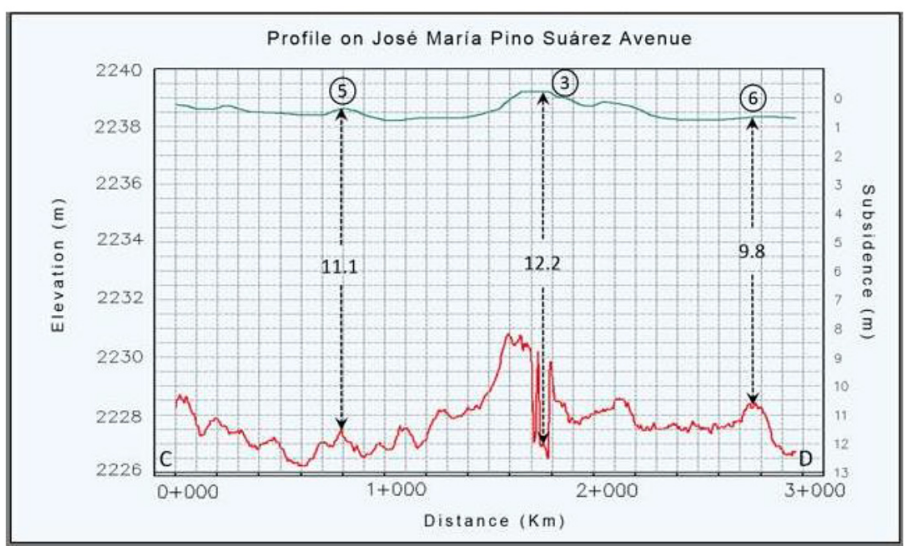

c) Profile along José María Pino Suárez Avenue (C-D)

Surface Profile, $1891 \quad$ Surface Profile, 2010

Figure 5. Location map and topographic profiles along Tacuba Avenue and J. M. Pino Suárez Avenue. 


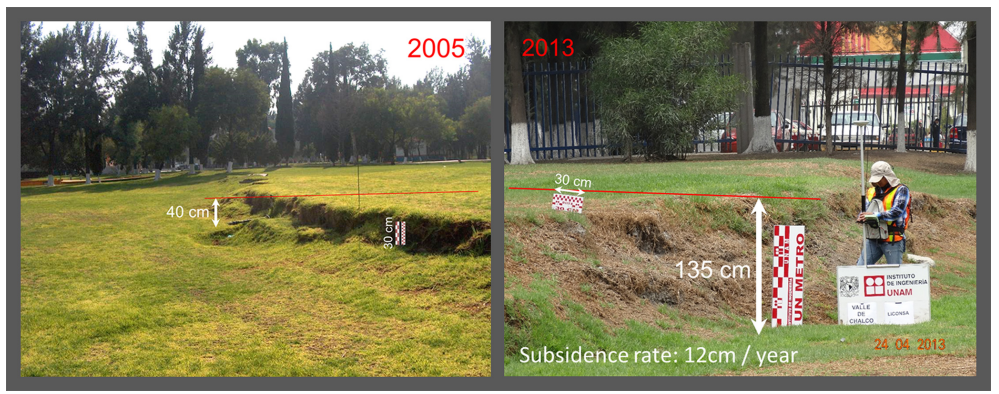

Figure 6. Crack with vertical step associated with the subsidence in abrupt transition zone.
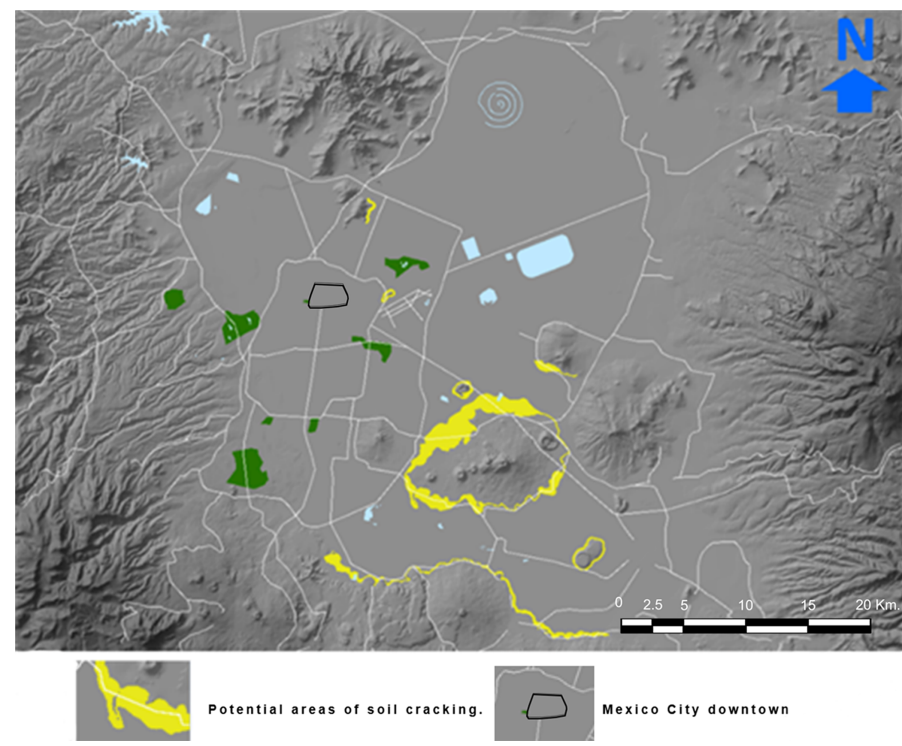

Figure 7. Main zones of Mexico City Valley subject to surface cracking (yellow strips).
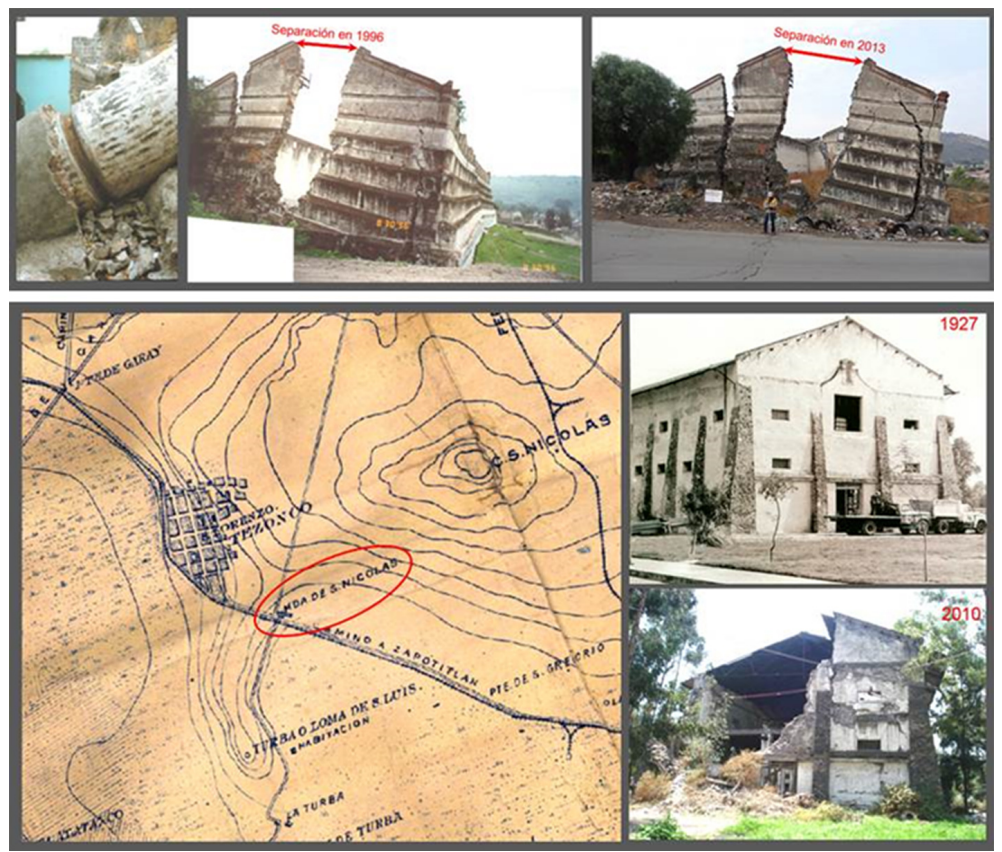

Figure 8. Effects of differential soil subsidence and cracks on constructions. 
promising results, but this is only the first stage of a huge job to be performed consistently in the future.

In a short period, it has been possible to update and expand the database of sites where cracks are found and to categorize them according to their mechanism of generation and/or propagation; further efforts will be necessary to define and extend the techniques to control the cracking phenomenon and mitigate its harmful effects.

Acknowledgements. The authors acknowledge the support of different institutions: Mapoteca Manuel Orozco y Berra, Palacio de Minería library, CONACYT, DGAPA-UNAM, IPN, GDF, CNA SACMEX and other institutions and agencies for the realization of this work. The valuable contributions from companies and geotechnical consultants who kindly gave to the authors access to their collections of subsoil explorations are also recognized.

\section{References}

Auvinet, G.: Agrietamiento de suelos, Proceedings, XXIV Reunión Nacional de Mecánica de Suelos, special volume, 299-313, Mexico, 2008.
Carrillo, N.: Influence of Artesian Wells on the Sinking of Mexico City, Proceedings of 2th Congress of International Soil Mechanics and Foundation Engineering, Vol. VI, 156-159, Rotterdam, 1948.

Fernandez Leal, M.: Carta Corográfica del Distrito Federal, Secretaría de Fomento, Official map, Mexico, 1899.

Gayol, R.: Plano General de las atarjeas conforme al proyecto de desagüe y saneamiento de la Ciudad de México, official map, Mexico, 1891.

Gayol, R.: A study of disturbances caused by draining out water from the subsoil of the Valley of Mexico, First part, Revista Mexicana de Ingenieria y Arquitectura, Vol. III, No. 3, 96-132; Second part, Revista Mexicana de Ingenieria y Arquitectura, Vol. III, No. 8, 507-559, Mexico, 1925 (in Spanish).

Instituto Nacional de Estadística, Geografía e Informática (INEGI): Data of LiDAR technology in Mexico City, data bases, Mexico, 2010.

Sistema de Aguas de la Ciudad de México: Set of topographic data of Mexico City, from 1977 to 2008, Mexico, 2008.

Téllez-Pizarro, A.: Apuntes acerca de los cimientos de los edificios en la ciudad de México, Reprinted in the commemorative volume of the XXV anniversary of the Mexican Society for Soil Mechanics (1982), Mexico, 1899. 